\title{
Pengaruh Waktu Reaksi Produksi Biodiesel dengan PFAD Menggunakan Katalis Karbon Kulit Ubi Kayu Tersulfonasi
}

\author{
Miranda Dwi Putri Gultom ${ }^{1}$, Umar Kalmar Nizar ${ }^{1 *}$, Edi Nasra ${ }^{1}$, Desy Kurniawati ${ }^{1}$ \\ Program Studi Kimia, Universitas Negeri Padang, Indonesia \\ 1E-mail: umarkn@fmipa.unp.ac.id
}

\begin{abstract}
Cassava peel carbon catalyst can be used in the production of biodiesel from PFAD. This catalyst is used because it is easily separated from the resulting biodiesel product and can be reused. Biodiesel production is carried out with time variations for 1 hour, 2 hours, 3 hours and 4 hours. The catalyst was characterized by determining the acid site and the resulting biodiesel was tested for physical properties of density test, flow rate, acid number and \% conversion. Determination of acid sites on sulfonated cassava peel carbon catalyst showed a value of $1.21 \mathrm{mmol} \mathrm{g}^{-1}$ which indicated that the sulfonation process was successful. Based on the results of testing the physical properties of biodiesel, the values for density, flow rate, and acid number were $0.8257 \mathrm{~g} / \mathrm{mL}$, $0.862 \mathrm{~mL} / \mathrm{s}, 22.4 \mathrm{mgKOH} / \mathrm{g}$, respectively. This result,
\end{abstract}

Keywords: Percent Conversion, PFAD, Sulfonation

\section{ABSTRAK}

Katalis karbon kulit ubi kayu dapat digunakan dalam produksi biodiesl dari PFAD. Katalis ini digunakan karena mudah dipisahkan dengan produk biodiesel yang dihasilkkan dan dapat digunakan kembali. Produksi biodiesel dilakukan dengan variasi waktu selama 1 jam, 2 jam, 3 jam dan 4 jam. Katalis dikarakterisasi dengan penentuan situs asam dan biodiesel yang dihasilkan di uji sifat fisika uji densitas, laju alir, bilangan asam dan \%konversi. Penentuan situs asam pada katalis karbon kulit ubi kayu tersulfonasi menunjukkan nilai sebesar 1.21 mmol. $\mathrm{g}^{-1}$ yang menandakan bahwa proses sulfonasi berhasil dilakukan. Berdasarkan hasil pengujian sifat fisika biodiesel, nilai densitas, laju alir, dan bilangan asam secara berturut-turut adalah $0.8257 \mathrm{~g} / \mathrm{mL}, 0.862 \mathrm{~mL} / \mathrm{s}, 22.4$ $\mathrm{mgKOH} / \mathrm{g}$. Hasil yang didaptkan ini, menunjukkan PFAD terkonversi menjadi biodiesel pada waktu reaksi selama 2 jam dengan \%konversi sebesar $87,67 \%$.

Kata Kunci: Persen Konversi ,PFAD, Sulfonasi

\section{PENDAHULUAN}

Waktu reaksi merupakan salah satu faktor yang mempengaruhi produksi biodiesel. Biodiesel dari katalis yang berbeda dengan sumber minyak nabati yang sama menunjukkan waktu reaksi optimum yang berbeda. Sebaliknya penggunakaan katalis yang sama dengan waktu reaksi berbeda menunjukkan persen konversi yang berbeda (1).

Produksi biodiesel dapat dilakukan dengan reaksi esterifkasi antara asam lemak bebas dengan alkohol rantai pendek (2). Asam lemak bebas umumnya diperoleh dari material limbah yang relatif lebih murah (3). Material limbah yang pernah dilaporkan untuk produksi biodiesel adalah limbah nabati seperti PFAD. Komposisi kimia PFAD adalah $85 \%$ asam lemak bebas, $10 \%$ trigliserida dan sisanya sterol, vitamin $\mathrm{E}$ dan squelene dalam jumlah kecil (4).

Katalis heterogen dapat berupa katalis basa padat dan asam padat. Katalis basa padat sesuai digunakan untuk bahan baku yang mengandung trigliserida sedangkan katalis asam padat sesuai untuk bahan baku yang mengandung FFA yang tinggi (1). Katalis asam padat lebih ramah lingkungan karena dapat mengurangi masalah korosif dan katalis ini tidak dipengaruhi konsentrasi asam lemak bebas dalam minyak. Sifat asam dari katalis dapat terjadi secara alami (zeolit), kombinasi dua oksida (5) atau sulfonasi/ sulfasi material (karbon tersulfonasi) (6)

Katalis karbon tersulfonasi dihasilkan dari substitusi gugus sulfonat ke dalam matriks karbon yang di sebut dengan sulfonasi (3). Sulfonasi karbon dari bahan pati dengan membentuk kepadatan yang tinggi dan situs aktif yang tinggi. Katalis ini juga menunjukkan aktifitas katalitik yang tinggi dan stabil serta dapat digunakan kembali (7).

Kulit ubi kayu mengandung pati yang tinggi dan juga terdapat sekitar $4-5 \%$ selulosa (8). Tingginya kandungan pati dan selulosa dari kulit ubi kayu tersebut, maka berpotensi sebagai sumber karbon untuk sintesis katalis asam padat berbasis karbon tersulfonasi. 


\section{METODE}

Penelitian ini merupakan penelitian eksperimental yang dilaksanakan di Laboratorium Kimia Universitas Negeri Padang pada bulan Januari - Juni 2021. Pada sintesis katalis digunakan metode kalsinasi kemudian dilanjutkan dengan proses sulfonasi dan esterifikasi untuk produksi biodiesel.

Peralatan yang digunakan yaitu furnace, statif dan klem, hotplate, magnetik stirrer, termometer, cawan penguap, lumpang dan alu, labu leher tiga, spinbar, erlenmeyer, labu ukur dan gelas kimia. Bahan yang digunakan adalah limbah kulit ubi kayu, H2SO4, aquades, PFAD dan metanol. Sampel kulit dicuci dan dikeringkan. Kemudian di oven pada suhu $105^{\circ} \mathrm{C}$ selama 24 jam (9). Sampel di kalsinasi pada suhu $450^{\circ} \mathrm{C}$ selama 1 jam (10) dan disimpan dalam desikator kemudian dihaluskan. Karbon yang dihasilkan dimasukkan ke dalam labu leher tiga sebanyak 5 gram kemudian dicampurkan dengan $100 \mathrm{~mL} \mathrm{H}_{2} \mathrm{SO}_{4}$ p.a dan direfluk pada suhu $160^{\circ} \mathrm{C}$ selama 4 jam. Hasil sulfonasi dinetralkan dengan aquades panas hingga $\mathrm{pH}$ aquades kemudian di oven pada suhu $105^{\circ} \mathrm{C}$ selama 24 jam.

Karakterisasi yang dilakukan terhadap biodiesel meliputi pengukuran densitas, laju alir, bilangan asam dan \% konversi.

\section{Pengukuran densitas}

Piknometer kosong ditimbang kemudian dimasukkan biodiesel. Setelah itu ditimbang piknometer yang sudah berisi biodiesel. Densitas sampel dihitung dengan rumus :

\section{Penentuan laju alir}

$$
\rho=\frac{\mathrm{W} 2-\mathrm{W} 1(\mathrm{~g})}{\mathrm{V}(\mathrm{mL})}
$$

Sebanyak $5 \mathrm{~mL}$ biodiesel dimasukkan ke dalam buret. Keran buret dibuka secara maksimal kemudian dicatat waktu sampai biodiesel habis. Nilai laju alir dihitung dengan rumus :

\section{Penentuan bilangan asam}

$$
\text { Laju alir }=\frac{\text { Volume }(m L)}{\text { Waktu }(s)}
$$

Sebanyak 0,5 gram biodiesel dicampurkan dengan $50 \mathrm{~mL}$ etanol. Kemudian dititrasi menggunakan $\mathrm{KOH}$ dalam etanol $0,5 \mathrm{~N}$ dengan indikator pp. Nilai bilangan asam dihitung dengan rumus :

\section{Penentuan \% konversi}

$$
\text { Bilangan Asam }=\frac{\mathrm{mL} \mathrm{KOH} \times \mathrm{N} \mathrm{KOH} \times \mathrm{BM} \mathrm{KOH}}{\text { Berat Sampel }}
$$
rumus:

Persen konversi biodiesel diperoleh dari nilai bilangan asam biodiesel. \% konversi dihitung dengan

$$
\% \text { Konversi }=\frac{\% F F A \text { minyak sumber }-\% \text { FFA biodiesel }}{F F A \text { minyak sumber }} \times 100 \%
$$

Kedalam labu leher tiga dimasukkan katalis sebanyak 3\% dan 15:1 metanol terhadap minyak lalu diaduk dengan kecepatan 100 rpm selama 10 menit. Secara perlahan masukkan 25 gram PFAD yang sudah di cairkan. Campuran kemudian di refluk pada suhu $64^{\circ} \mathrm{C}$ dengan kecepatan $300 \mathrm{rpm}$ selama 1 jam, 2 jam , 3 jam dan 4 jam. Setelah reaksi selesai dilakukan proses sentrifuga pada 10000 rpm selama 10 menit. Biodiesel yang dihasilkan kemudian di uji denitas, laju alir, bilangan asam dan \% konversinya.

\section{HASIL DAN PEMBAHASAN}

Penentuan situs asam yang dianalisis menggunakan metode titrasi asam basa bertujuan untuk mengetahui jumlah situs asam yang terkandung dalam karbon kulit ubi kayu tersulfonasi. Data dari situs asam dapat dilihat pada Gambar 1. Berdasarkan Gambar 1, jumlah situs asam pada karbon kulit ubi kayu yang semula $0 \mathrm{mmol} . \mathrm{g}^{-1}$ meningkat pada katalis karbon kulit ubi kayu yaitu sebesar $1.21 \mathrm{mmol} . \mathrm{g}^{-1}$. Hasil ini menunjukkan gugus sulfonat berhasil disubstitusi pada permukaan karbon 


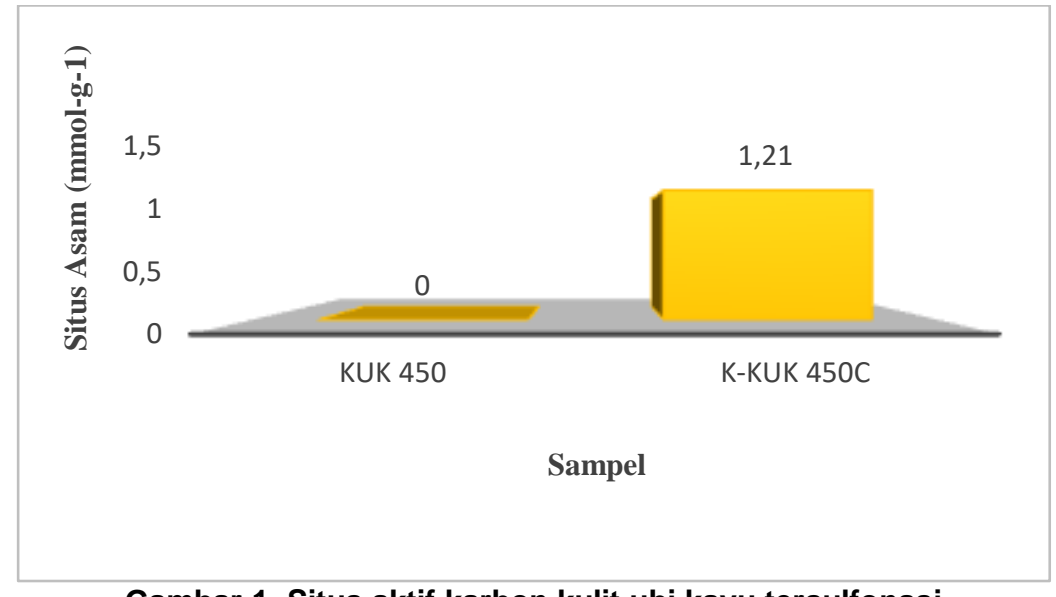

Gambar 1. Situs aktif karbon kulit ubi kayu tersulfonasi

Densitas diukur menggunakan piknometer dan dibandingkan dengan standar yang berlaku. Hasil pengujian densitas dapat dilihat pada Gambar 2 yang menunjukkan pada waktu reaksi 1 jam dan 2 jam densitas mengalami penurunan yaitu dari $0,8435 \mathrm{~g} / \mathrm{mL}$ menjadi $0,8257 \mathrm{~g} / \mathrm{mL}$. Penurunan nilai densitas ini disebabkan konversi asam lemak menjadi molekul yang lebih kecil yaitu metil ester asam lemak (11). Kemudian densitas mengalami kenaikan pada waktu reaksi 3 jam dan 4 jam yaitu dari 0,8281 g/mL menjadi 0,8473 g/mL.

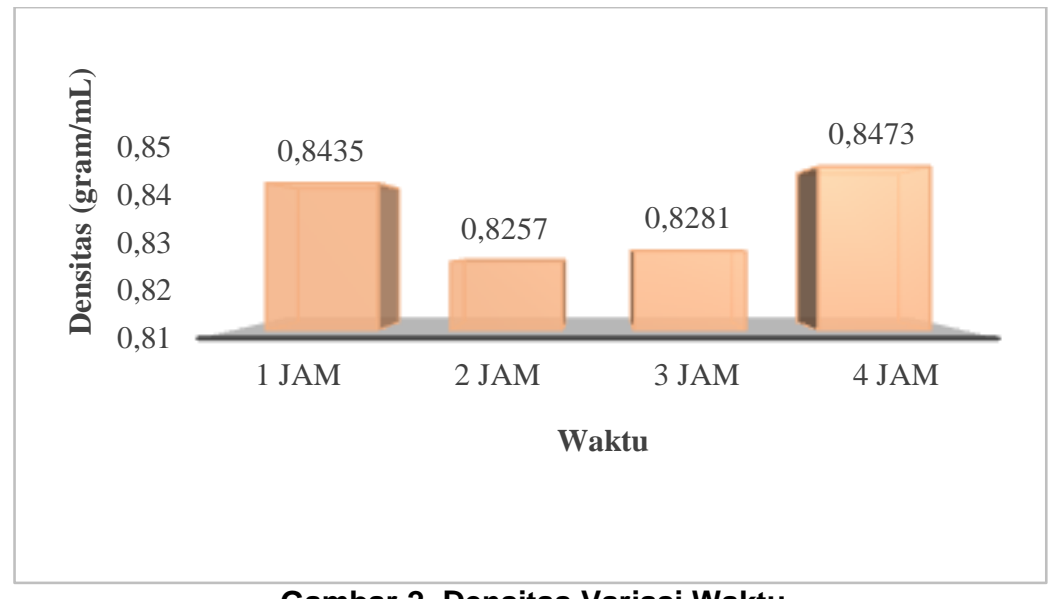

\section{Gambar 2. Densitas Variasi Waktu}

Semakin tinggi laju alir biodiesel maka semakin rendah viskositasnya. Viskositas yang rendah akan membuat biodiesel lebih mudah mengalir dan teratomisasi (12). Hasil penentuan laju alir dapat dilihat pada Gambar 3 yang menunjukkan bahwa semakin lama waktu reaksi maka laju alir semakin meningkat, yaitu pada waktu reaksi 1 jam dan 2 jam laju alir meningkat dari $0,8333 \mathrm{~mL} / \mathrm{s}$ menjadi $0,862 \mathrm{~mL} / \mathrm{s}$. Peningkatan laju alir disebabkan oleh semakin tingginya konversi biodiesel yang dihasilkan. Kemudian laju alir mengalami penurunan pada waktu reaksi 3 jam ke 4 jam yaitu dari $0,8196 \mathrm{~mL} / \mathrm{s}$ menjadi $0.7692 \mathrm{~mL} / \mathrm{s}$. Penurunan laju alir ini dapat disebabkan oleh keberadaan kandungan air dan metanol dalam biodiesel (13)

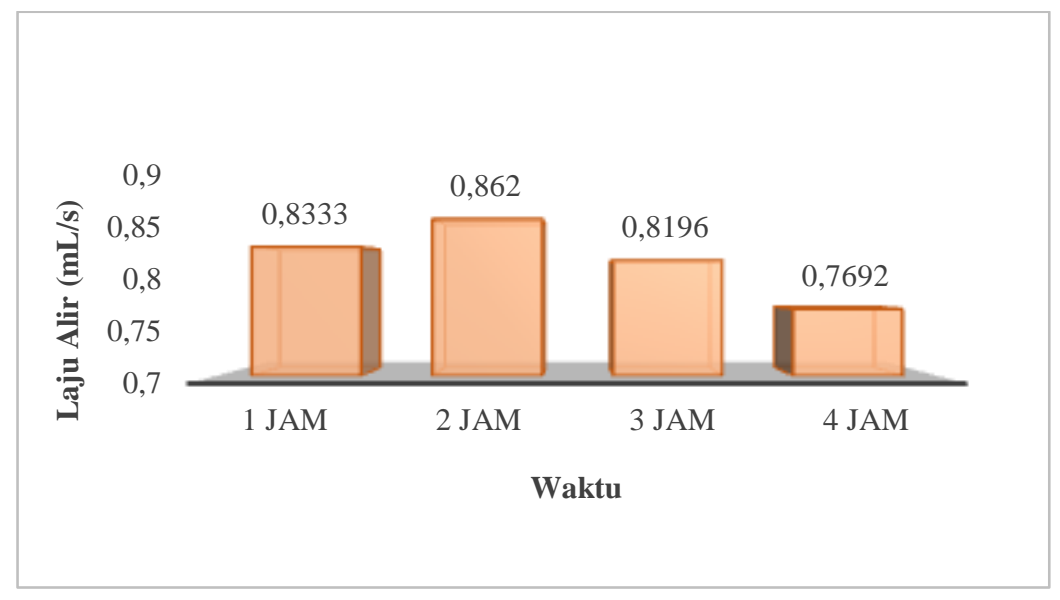




\section{Gambar 3. Laju Alir Variasi Waktu}

Kandungan asam lemak bebas yang tinggi dalam biodiesel dapat menimbulkan jelaga atau kerak di injektor mesin diesel karena bersifat korosif. Data bilangan asam dapat dilihat pada Gambar 4. Berdasarkan Gambar 4, bilangan asam semakin penurunan seiring bertambahnya waktu reaksi yaitu dari waktu 1 jam dan 2 jam sebesar $61,6 \mathrm{mgKOH} / \mathrm{g}$ menjadi $22,4 \mathrm{mgKOH} / \mathrm{g}$. Kemudian pada waktu reaksi 3 jam dan 4 jam bilangan asam mengalami peningkatan yaitu dari $33,6 \mathrm{mgKOH} / \mathrm{g}$ menjadi $123,2 \mathrm{mgKOH} / \mathrm{g}$.

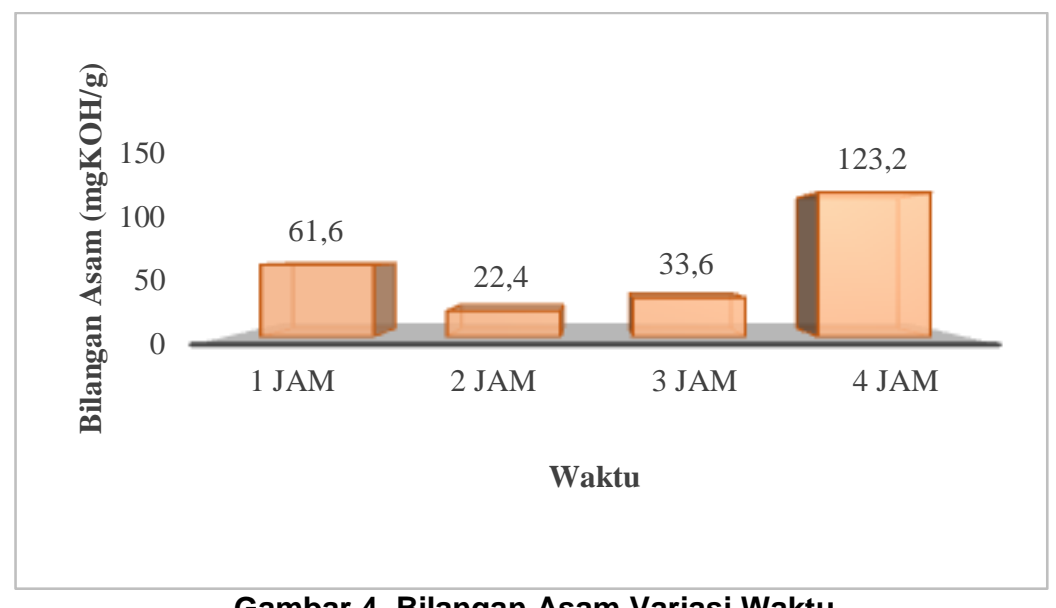

Gambar 4. Bilangan Asam Variasi Waktu

Persen konversi biodiesel dapat dihitung dari data bilangan asam yang diperoleh. Data persen konversi disajikan pada Gambar 5, dapat diketahui bahwa persen konversi semakin meningkat seiring bertambah lamanya waktu reaksi yaitu pada waktu 1 jam dan 2 jam sebesar 66,09\% menjadi 87,67\%. Persen konversi meningkat dikarenakan reaksi telah mencapai kesetimbangan. Tetapi ketika waktu reaksi semakin lama persen konversi kembali menurun yaitu pada waktu reaksi 3 jam dan 4 jam sebesar 81,50\% menjadi $32,19 \%$. Penurunan ini disebabkan oleh berkurangnya metil ester asam lemak karena terjadinya hidrolisis biodiesel dalam kondisi basa (14).

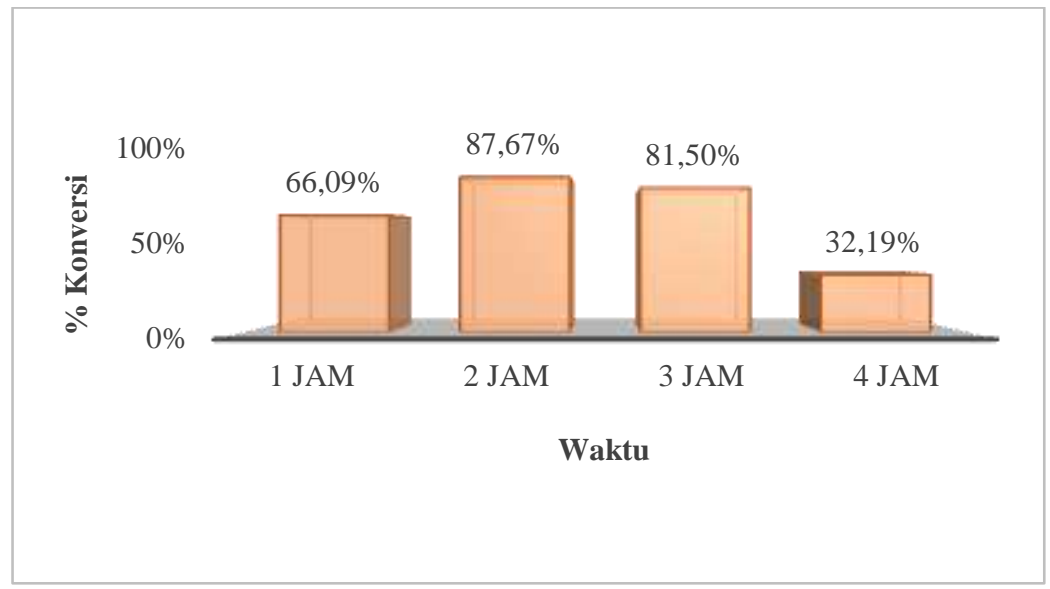

Gambar 5. \% Konversi Variasi Waktu

\section{KESIMPULAN}

Jumlah situs asam pada katalis karbon kulit ubi kayu meningkat menjadi 1,21 mmol.g ${ }^{-1}$ dari karbon kulit ubi kayu yang jumlah situs asamnya $0 \mathrm{mmol} . \mathrm{g}^{-1}$. Hal ini membuktikan bahwa gugus sulfonat berhasil disubstitusi pada permukaan karbon pada proses sulfonasi.

Setelah dilakukan uji densitas, laju alir, bilangan asam dan \%konversi terhadap biodiesel, didapatkan waktu reaksi optimum untuk produksi biodiesel adalah 2 jam dengan hasil persen konversi sebesar $87,67 \%$.

\section{REFERENSI}

1. Talha NS, Sulaiman S. Overview of catalysts in biodiesel production. ARPN J Eng Appl Sci. 2016;11(1):439-42.

2. Borah MJ, Devi A, Saikia RA, Deka D. Biodiesel production from waste cooking oil catalyzed by in-situ decorated TiO2 on reduced graphene oxide nanocomposite. Energy [Internet]. 2018;158:881-9. Available from: https://doi.org/10.1016/j.energy.2018.06.079

3. Mansir N, Hwa S, Rabiu I, Hin Y. E ff ective biodiesel synthesis from waste cooking oil and biomass 
residue solid green catalyst. 2018;347(December 2017):137-44.

4. Akinfalabi SI, Rashid U, Yunus R, Taufiq-Yap YH. Synthesis of biodiesel from palm fatty acid distillate using sulfonated palm seed cake catalyst. Renew Energy. 2017;111:611-9.

5. Nizar UK, Efendi J, Yuliati L, Gustiono D, Nur H. A new way to control the coordination of titanium (IV) in the sol-gel synthesis of broom fibers-like mesoporous alkyl silica-titania catalyst through addition of water. Chem Eng J. 2013;222:23-31.

6. Farabi MSA, Ibrahim ML, Rashid U, Taufiq-Yap YH. Esterification of palm fatty acid distillate using sulfonated carbon-based catalyst derived from palm kernel shell and bamboo. Energy Convers Manag. 2019;181(December 2018):562-70.

7. Wang M, Wu W, Wang S, Shi X, Wu F, Wang J. Preparation and Characterization of a Solid Acid Catalyst from Macro Fungi Residue for Methyl Palmitate Production. BioResources. 2015;10(3):5691708.

8. Wang S, He H, Yu J, Chen S, Li X, Bo F, et al. Cellulase-added cassava ethanol process boosts ethanol titer and reduces glycerol production. Ind Crops Prod [Internet]. 2020;148(November 2019):112304. Available from: https://doi.org/10.1016/j.indcrop.2020.112304

9. Lokman IM, Rashid U, Taufiq-Yap YH, Yunus R. Methyl ester production from palm fatty acid distillate using sulfonated glucose-derived acid catalyst. Renew Energy. 2015;81:347-54.

10. Gemasih MIS, Gustia N, Umar N, Nizar K, Dewata I, Nasra E, et al. Calcination for Future Application. $2021 ;(2): 202-8$.

11. Atabani AE, Silitonga AS, Badruddin IA, Mahlia TMI, Masjuki HH, Mekhilef S. A comprehensive review on biodiesel as an alternative energy resource and its characteristics. Renew Sustain Energy Rev [Internet]. 2012;16(4):2070-93. Available from: http://dx.doi.org/10.1016/j.rser.2012.01.003

12. Sundaryono A. Karakteristik Biodiesel Dan Blending Biodiesel Dari Oil Losses Limbah Cair Pabrik Minyak Kelapa Sawit Characteristic of Biodisesel and Biodiesel Blending of Oil Losses From Liquid Waste of Oil Palm Factory. 2010;2041.

13. Farianty D, Putra A, Dj L, Nizar UK. Biodiesel Production from Palm and Waste Cooking Oils Catalyzed by Silica-Titania Catalyst with Time Variation. 2019;4(7):4-8.

14. Abbah EC, Nwandikom GI, Egwuonwu CC, Nwakuba NR. Effect of Reaction Temperature on the Yield of Biodiesel From Neem Seed Oil. Am J Energy Sci. 2016;3(3):16-20. 